\title{
Stress tolerant rhizobia inhabiting the root nodules of Gliricidia sepium from selected locations of Anuradhapura district, Sri Lanka
}

V.R.R.U. Udapamunuwa ${ }^{1,2}$, P.W.I. Nawanjana ${ }^{2}$, S. Rajapakse ${ }^{2 *}$

${ }^{1}$ Post Graduate Institute of Science, University of Peradeniya, Sri Lanka

\section{${ }^{2}$ Department of Molecular} Biology and Biotechnology, Faculty of Science, University of Peradeniya, Sri Lanka

\section{Correspondence:}

2sanathr@pdn.ac.lk

ORCID: 0000-0002-0014-5811

\begin{abstract}
The symbiotic association between Rhizobium and leguminous species plays a significant role in sustainable agricultural systems as it contributes higher amounts of fixed nitrogen to soil through biological nitrogen fixation. Gliricidia sepium is one of the most commonly cultivated agro forestry trees in the world. This leguminous tree is widely distributed throughout Sri Lanka. A very limited number of studies are available on G. sepium-Rhizobium symbiosis in Sri Lanka. The main objective of this study is to isolate and identify the stress tolerant Rhizobium sp. in G. sepium as a preliminary approach to use rhizobial strains for cross inoculation of crop legumes in order to minimize the heavy use of chemical nitrogen fertilizers. The root nodules of $G$. sepium were collected from seven sites in Anuradhapura district which is located in the dry zone of Sri Lanka. A total of 34 strains were tested for their tolerance to different physiological conditions namely $\mathrm{pH}$, salinity, drought and temperature. Fifteen strains showed a higher tolerance among the isolated 34 strains when grown under a wide range of physiological conditions. When these 15 stress tolerant rhizobial strains were grown under extreme physiological conditions, 12 strains could survive well as they often experience adverse environmental conditions in their natural habitat. DNA fingerprinting analysis with ERIC $1 \mathrm{R}$ and ERIC $2 \mathrm{R}$ showed that the 15 strains are genetically diverse and they belong to 9 clusters at $71 \%$ similarity level.
\end{abstract}

Keywords: Biological nitrogen fixation, DNA fingerprinting, Genetic diversity, G. sepium, Rhizobium stress tolerance 


\section{Introduction}

Biological nitrogen fixation and the symbiotic relationship between Rhizobia and legumes play a significant role in reinvigorating sustainable agricultural practices to increase world food production and provide adequate food for the growing human population (Laranjoa et al. 2014). Excessive use of industrially produced chemical $\mathrm{N}$ fertilizers had contributed to major health problems to mankind and hazards to the environment and biological nitrogen fixation could provide better solutions to them (Bohlool et al. 1992). Biological nitrogen fixation is a process in which atmospheric nitrogen is converted to ammonia, a plant usable form by microorganisms. This reaction is catalyzed by the enzyme nitrogenase which is found in prokaryotic microorganisms (Cheng 2008). This biological process is an efficient method of delivering nitrogen to the plants (Peoples et al. 1995). According to Burns and Hardy (1975) and Paul (1988) biological nitrogen fixation contributes 139 to 175 million tonnes of nitrogen to terrestrial eco systems per year.

The symbiotic relationship of Rhizobia with legumes acquires a higher value as it is capable of fixing $30-40 \mathrm{Kg}$ of nitrogen for every tonne of total dry mass produced by crop legumes (Peoples et al. 2009). The global attention on legumes is increasing day by day as they play a significant role in some fields such as agriculture and ecology (Zahran 1999). It is estimated that approximately about $20 \%$ of legumes have the capacity for nodulation and nitrogen fixation among 700 genera and 13000 species (Sprent and Sprent 1990). Nodule is a structure which contains all the required modifications to carry out biological nitrogen fixation successfully and they can be seen on the roots of most of the legumes (Sprent 2009) belonging to the subfamilies Papillionoideae (97\%) and Mimosoideae (90\%) Kulasooriya (2008). Rhizobium is a rod-shaped, gram negative, soil bacterium which does not form spores (Kumari and Sinha 2001).

Currently, the family Rhizobiaceae consists of different genera such as Rhizobium, Azorhizobium, Mesorhizobium, Bradyrhizobium, Allorhizobium and Sinorhizobium (Kumar and Ram 2012).

Black pepper, Coffee and Cocoa are some of the well-known perennial crops grown in the mid country region of Sri Lanka. Gliricidia sepium is the most commonly grown leguminous tree species in these agro-forestry systems in order to provide shade for the crops (Gunaratne et al. 2000). G. sepium is a member of family Fabaceae (Lavin et al. 1991) and this plant species is utilized for several purposes other than as a shade tree such as fuel wood, crop support, green manure, fodder and also to stabilize soils and prevent erosion (Simons and Stewart 1994). According to Jayasundara et al. (1997), G. sepium was identified as a high $\mathrm{N}$ fixer by confirming the experimental results submitted by several workers and it was shown that this legume species has the potential of obtaining 52\% - 74\% of its $\mathrm{N}$ from the atmosphere (Awonaike et al. 1992; Liyanage et al. 1994). G. sepium has the ability to enhance soil fertility and productivity when intercropped with coconut (Liyanage et al. 1988). 
Anuradhapura district is located in the North Central Province of Sri Lanka. According to the data of the Sri Lankan Department of Meteorology, The Anuradhapura district has an average annual temperature of $27.3{ }^{\circ} \mathrm{C}$ and receives $1368 \mathrm{~mm}$ of average rainfall annually. In his report on Anuradhapura district environmental profile submitted to Central Environmental Authority of Colombo Handawela (1992) indicates the soil type of this area as well-drained, reddish brown, while its $\mathrm{pH}$ varies from 5.0-8.0 (Renuka and Senevirathne 2017). G. sepium is widely distributed all over Sri Lanka due to its ability to grow in a wide range of soil types and also the ability to withstand common pest diseases (Chadhokar 1982). Although there are many studies carried out throughout the world to investigate nitrogen fixing efficiency of rhizobial strains with different plant species, only a few research studies have been reported on $G$. sepium-Rhizobia symbiosis in Sri Lanka (Samarakoon and Rajapakse 2020). According to Stamford et al. (1997) nitrogen has been identified as one of the growth limiting factors of plants. It has been found that nitrogen fixing ability of Rhizobia is strongly dependent on the bacterial strain and the host plant species and it can go up to $450 \mathrm{kgNh}^{-1}$. Taking these facts into consideration the best rhizobial strains which exhibit a high performance in the field even under adverse climatic conditions can be used as bio-fertilizers in agriculture (Rai 2006).

Enterobacterial Repetitive Intergenic Consensus (ERIC) sequences are imperfect palindromes found in non-coding, intergenic regions of bacterial genomes. These repetitive units are of
127 bp in size (Wilson and Sharp 2006). From the Sharples and Lloyd (1990) and Hulton et al. (1991) the sequences were first discovered in the genomes of Escherichia coli, Salmonella typhimurium, Enterobacteriaceae and Vibrio cholerae, the individual genotype of different rhizobial strains affects their efficiency for modulating the host plant and also the symbiotic nitrogen fixation. Hence, accurate and efficient strain identification and classification methods are required and it is done through DNA fingerprinting technique which relies in Polymerase Chain Reaction (PCR) using ERIC sequences as primers, as they are capable of producing strain specific fingerprints (Niemann et al. 1999). Therefore, the main objectives of this study were to isolate rhizobial strains from selected areas in Anuradhapura district and to do physiological characterization of isolated rhizobial strains. And also to check their tolerance to environmental conditions such as $\mathrm{pH}$, salinity, temperature and drought and thereby to determine the genetic diversity of stress tolerant rhizobial strains using ERIC-PCR based DNA fingerprinting technique.

\section{Materials and Methods}

\section{Collection of root nodules and Isolation of} Rhizobia

Root nodules were collected from seven different sites in Anuradhapura district in Sri Lanka (Kailapathana, Galkulama, Thambuththegama, Kebithigollewa, Medawachchiya, Horowpothana, Anuradhapura urban area). A single host plant was selected from each location to have a total of seven plants and five nodules were collected from each host plant (G. sepium) except for the plant from the 
site Kailapathana where only four nodules were collected. All the 34 nodules from seven host plants were surface sterilized and cultured separately using the Crush method to isolate a single Rhizobium strain from each nodule. The nodule suspension for each nodule was streaked separately on the prepared 1/2 Lupin Agar (LA) medium and the labelled culture plates were incubated at room temperature for 3-4 days in dark (Somasegaran and Hoben 1994). Pure rhizobial colonies were obtained by subculturing 4-5 times.

\section{Tolerance of Rhizobia for physiological conditions}

The $\mathrm{pH}$ tolerance was assessed by culturing the isolated 34 strains in $1 / 2$ Lupin broth at $\mathrm{pH}$ values ranging from 3.0-10.0. Salinity tolerance was tested for six $\mathrm{NaCl}$ concentrations $(0.1 \%, 1 \%$, $1.5 \%, 2 \%, 2.5 \%$, and $3 \%$ ) in $1 / 2$ Lupin broth and drought stress was induced by adding Polyethylene Glycol-8000 (PEG-8000) at different concentrations $(0.1 \%, 0.2 \%, 0.3 \%$, and $0.4 \%$ ). The cultures were incubated at room temperature $\left(27^{\circ} \mathrm{C}\right)$ for three days in dark. The tolerance for the temperature was assessed by incubating the cultures at five different temperatures $\left(25^{\circ} \mathrm{C}, 30^{\circ} \mathrm{C}, 35^{\circ} \mathrm{C}, 40^{\circ} \mathrm{C}\right.$, and 45 ${ }^{\circ} \mathrm{C}$ ). The growth of rhizobial isolates under these conditions was assessed by measuring the optical absorbance at $600 \mathrm{~nm}$ wave length using the UV Spectrophotometer (Analytik JenaSPECORD ${ }^{\circledR} 200$, Germany).

\section{Tolerance for combination of different conditions}

The rhizobial strains that showed high tolerance to the different conditions were selected and those samples were treated with combinations of selected $\mathrm{pH}(8.0)$, salinity $(3.0 \% \mathrm{NaCl})$ and drought conditions $(0.4 \% \quad$ PEG) and were incubated at $36{ }^{\circ} \mathrm{C}$ for three days. The absorbance at $600 \mathrm{~nm}$ was measured to determine the growth of rhizobial strains.

\section{DNA fingerprinting with ERIC primers}

Genomic DNA of 15 selected isolates were extracted using phenol chloroform method and DNA fingerprinting was carried out for the isolated rhizobial strains using ERIC $1 R$ and ERIC $2 R$ primers. The amplified DNA fragments were visualized using Agarose Gel electrophoresis.

\section{Data analysis and representation}

The growth of rhizobial strains for all conditions in all the seven sites were compared by plotting line graphs. A dendogram was prepared for the rhizobial strains that showed tolerance to extreme conditions by Complete Linkage Euclidean Distance using the software MINITAB 18.

\section{Results}

\section{pH tolerance of Rhizobial strains}

The $\mathrm{pH}$ tolerance of rhizobial strains was determined within the range of 3.0-10.0. All the 34 strains from all seven sampling sites exhibited their highest growth within $\mathrm{pH}$ 5-7. Most of the rhizobial strains showed a poor growth within the acidic $\mathrm{pH}$ range of 3-4. But the rhizobial strains isolated from the site, Medawachchiya showed a better growth even at this acidic $\mathrm{pH}$ range compared to the strains from other sites. There was poor growth of the rhizobial strains also at the alkaline $\mathrm{pH}$ (9-10) except the strains from Medawachchiya site 
which showed a considerable growth. Almost all the strains showed a better growth in acidic $\mathrm{pH}$ compared to alkaline pH (Fig. 1).

There was no gradually increasing growth pattern of rhizobial strains in any of the sites when changing $\mathrm{pH}$ from 3 to 5 . A reduction in growth was observed only for the site, Medawachchiya on increasing $\mathrm{pH}$ from 3 to 5 (Fig. 1 G). In the site Kailapathana, the highest growth was observed in strain $\mathrm{K}-\mathrm{c}$ at pH 6.0 and the minimum growth was observed in K-a strain at $\mathrm{pH}$ 3.0. K-a and K-b strains showed their maximum growth at $\mathrm{pH} 5.0$ while $\mathrm{K}$-d strain showed its highest growth at $\mathrm{pH}$ 7.0. The strains $\mathrm{K}-\mathrm{b}$ and $\mathrm{K}-\mathrm{c}$ grew considerably in all $\mathrm{pH}$ values compared to K-a and K-d strains. The growth of $\mathrm{K}-\mathrm{b}, \mathrm{K}-\mathrm{c}$ and $\mathrm{K}-\mathrm{d}$ was almost similar at $\mathrm{pH} 8.0$ (Fig. $1 \mathrm{~A}$ ). The highest growth was showed by Gl$\mathrm{d}$ at $\mathrm{pH} 5.0$ and the least growth was showed by Gl-e at pH 3.0 in Galkulama site. A higher growth was observed in Gl-d at $\mathrm{pH} 5.0$ and $\mathrm{pH} 7.0$ (>0.400). Except Gl-b, the other three strains exhibited a considerable growth at $\mathrm{pH} 9.0$ when compared to $\mathrm{pH} 8.0$ and 10.0 (Fig. 1 B). In Anuradhapura, the maximum growth was observed in Ap-c at pH 6.0 (0.595) and the growth of Ap-d strain at pH $5.0(0.570)$ was not significantly different from it. Ap-d showed the minimum growth $(0.060)$ at $\mathrm{pH} 3.0$ and a reduction in growth of the rhizobial strains was observed on increasing pH from 8.0 to 10.0 (Fig. $1 \mathrm{C})$. The highest growth was exhibited by Hr-e at pH 5.0 and the least growth was exhibited by Hr-a, at pH 10.0 in Horowpothana.
The strain Hr-e showed a substantial growth at pH 6.0 and 7.0 other than pH 5.0 and almost all the 5 strains grew well at pH 7.0. The growth of the rhizobial strains at highly acidic $\mathrm{pH}$ was more compared to their growth at highly alkaline $\mathrm{pH}$ (Fig. 1 E). In the site Thambuththegama, the highest growth was observed in Tb-a at pH 7.0 while the least growth was observed in Tb-e at pH 9.0. All the 5 strains showed a better growth at $\mathrm{pH}$ 7.0. The growth of the rhizobial strains was less at $\mathrm{pH} \quad 10.0$ compared to the growth at pH 8.0 and 9.0 (Fig. 1 D). Kb-c strain showed the highest growth in Kebithigollewa which was at pH 5.0 and the least growth was shown by Kb-d strain at $\mathrm{pH}$ 9.0. A considerable growth pattern was observed in the strain $\mathrm{Kb}-\mathrm{c}$ at all $\mathrm{pH}$ values compared to other four strains. A high growth was exhibited by $\mathrm{Kb}-\mathrm{c}$ at highly alkaline $\mathrm{pH}$, in which other strains showed a poor growth (Fig. 1 F). The maximum and the minimum growth was observed in the same strain, Md-a in the site Medawachchiya at $\mathrm{pH} \quad 6.0$ and $\mathrm{pH} \quad 9.0$ respectively. Md-d showed a significant growth at highly acidic $\mathrm{pH}(\mathrm{pH} 3.0$ and $\mathrm{pH} 4.0)$ and a substantial amount of growth at pH.8.0 compared to pH 9.0 and 10.0 (Fig. 1 G) showed a considerable growth at highly acidic $\mathrm{pH}$ compared to highly alkaline $\mathrm{pH}$. A- Graph for the site Kailapathana (K). B- Graph for the site Galkulama (Gl). C- Graph for the site Anuradhapura (Ap). D- Graph for the site Thambuththegama (Tb). E- Graph for the site Horowpothana (Hr). F- Graph for the site Kebithigollewa (Kb). G- Graph for the site Medawachchiya (Md). 


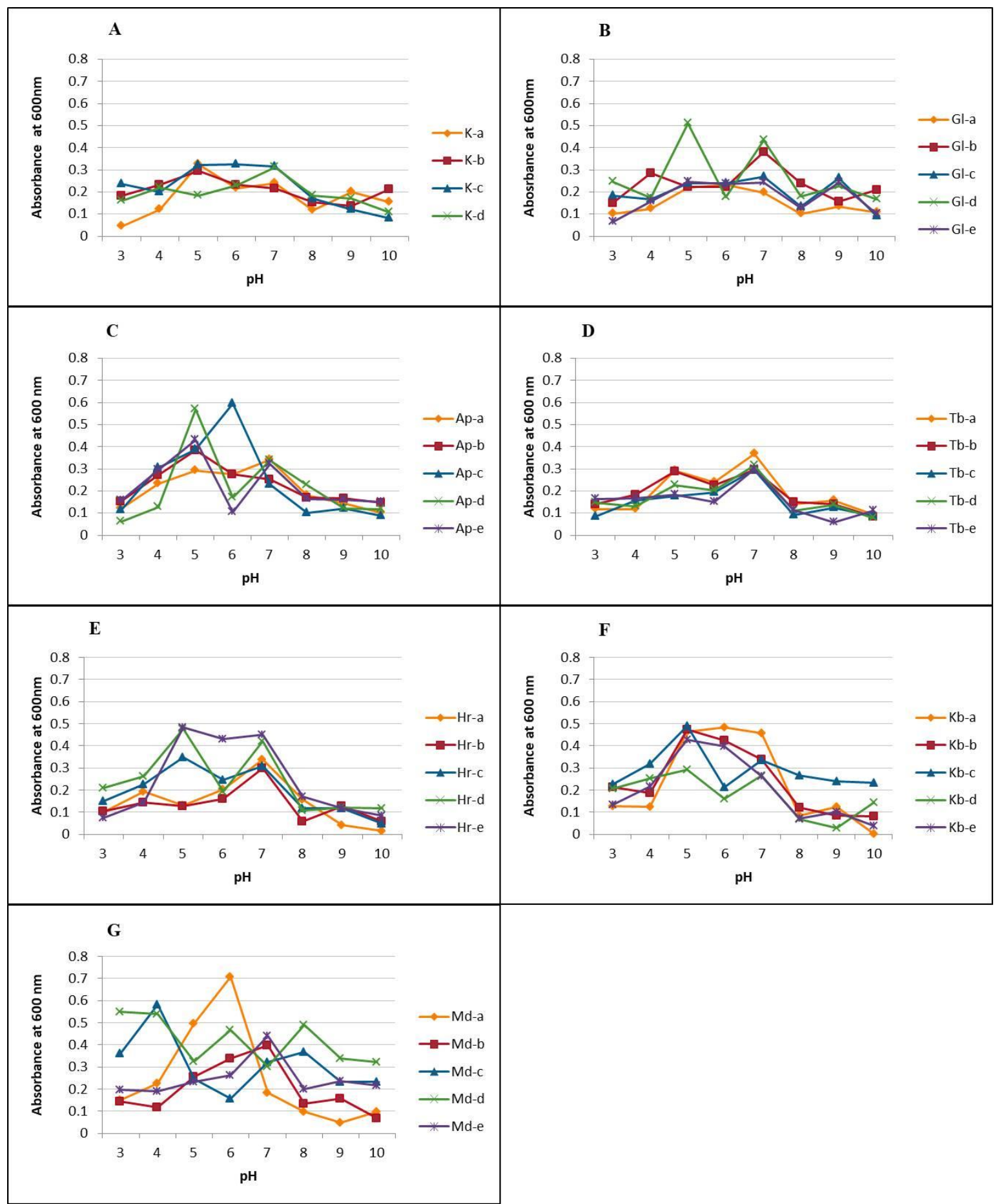

Figure 1. Growth of isolated rhizobial strains from seven sites at different $\mathrm{pH}$ values.

Five strains from each sampling site obtained from the single host plant were grown under different $\mathrm{pH}$ varying from 3.0-10.0. Growth was determined by the optical absorbance at $600 \mathrm{~nm}$. The growth pattern was almost similar in all the sites where the highest growth was observed in the $\mathrm{pH}$ range from 5.0 to 7.0. Most of the strains of each site.

\section{Salinity tolerance of rhizobial strains}

The tolerance of isolated rhizobial strains for salinity was analyzed by making them to grow in the medium with a series of $\mathrm{NaCl}$ concentrations starting from $0.1 \%$ and goes up to $3.0 \%(0.1 \%$, $1.0 \%, 1.5 \%, 2.0 \%, 2.5 \%$ and $3.0 \%$ ). There was no clearly observable growth pattern of isolated rhizobial strains in all the seven sampling sites when increasing $\mathrm{NaCl}$ concentration (Fig. 2). 
The highest growth was observed in K-a strain at $1 \% \mathrm{NaCl}$ and the minimum growth was shown by $\mathrm{K}-\mathrm{b}$ at $1.5 \% \mathrm{NaCl}$ in Kailapathana. Almost all the strains of each site have grown well at 1.0\% and $3.0 \% \mathrm{NaCl}$ concentration levels. The three strains K-a, K-c and K-d showed substantial amounts of growth at all the $\mathrm{NaCl}$ concentrations (Fig. 2 A). In the site Galkulama, Gl-a showed the maxiumum growth at $3.0 \% \mathrm{NaCl}$ and the strain Gl-b showed the minimum growth at the same $\mathrm{NaCl}$ concentration. The growth of Gl-b strain has decreased on increasing $\mathrm{NaCl}$ concentration from $1.5 \%$ to $3.0 \%$ and its growth has changed drastically from $1.5 \%(0.452)$ to $2.0 \%(0.242)$ $\mathrm{NaCl}$ concentration levels (Fig. $2 \mathrm{~B}$ ). The highest growth was observed in Ap-c at 1.0\% NaCl and the least growth was observed in Ap-e at 2.5\% $\mathrm{NaCl}$ concentration in Anuradhapura urban area. All the 5 strains exhibited a better growth at $1.0 \%$ of $\mathrm{NaCl}$. A drastic increase in growth was observed in Ap-c when increasing the salinity level from 2.5\% (0.201) to 3.0\% (0.390) (Fig. 2 C). The highest absorbance value was shown by Tb-b strain by indicating the maximum growth in Thambuththegama site while $\mathrm{Tb}-\mathrm{d}$ showed the lowest absorbance value by indicating the minimum growth. The strain $\mathrm{Tb}$-a could survive under all salinity levels $(>0.230)$ compared to other four strains (Fig. 2 D). In the site Horowpothana, the highest growth was observed in $\mathrm{Hr}$-a at $2.5 \% \mathrm{NaCl}$ and the lowest growth was observed in Hr-e at the same salinity level. The growth of Hr-b was almost similar within $0.1 \%$ to $1.5 \%$ salinity range and it has increased on increasing the concentration from $2.0 \%$ to $3.0 \%$ (Fig. 2 E). The highest growth was indicated by $\mathrm{Kb}-\mathrm{b}$ at $2.5 \%$ salinity level and the least growth was indicated by $\mathrm{Kb}-\mathrm{c}$ at the same salinity level in Kebithigollewa site. A similar growth pattern was observed in the two strains $\mathrm{Kb}-\mathrm{c}(0.383)$ and $\mathrm{Kb}-\mathrm{d}(0.384)$ at $3.0 \% \mathrm{NaCl}$ (Fig. 2 F). In the site Medawachchiya, the highest growth was shown by Md-e at $1.0 \%$ salinity level while Md-d showed the lowest growth at 2.5\% $\mathrm{NaCl}$. The strain Md-c has survived well under all the salinity levels and the growth level of Md-b was almost similar from $0.1 \%$ to $2.5 \%$ salinity range (Fig. 2 G).

\section{Drought tolerance of rhizobial strains}

Polyethylene glycol (PEG) was added to the culture medium to create a drought condition and a drought series with different PEG concentrations was prepared. No clear pattern of growth in response to changing drought conditions was observed. The highest growth was observed in Md-b among all the 34 strains at $0.4 \%$ PEG (Fig. 3).

In the site Kailapathana, K-b showed the highest growth at $0.1 \%$ PEG. The least growth was observed in K-d at 0.3\% PEG. The two strains Ka and K-c were survived well even at 0.4\% PEG $(>0.450)$. All the five strains could grow well at $0.1 \%$ PEG (>0.500) (Fig. $3 \mathrm{~A}$ ). Gl-c showed the maximum growth at $0.1 \%$ PEG in Galkulama site. The minimum growth was shown by Gl-b at $0.4 \%$ PEG. Except the three strains Gl-a, Gl-b and Gl-e, the remaining two strains Gl-c and G-d could grow considerably at $0.4 \%$ PEG (Fig. 3 B). In the site Anuradhapura, the growth level of the five strains at $0.3 \%$ and $0.4 \%$ PEG concentrations was almost similar. The highest growth was observed in Ap-c and the least growth was observed in Ap-a. When increasing the PEG concentration, the growth of Ap-c strain 


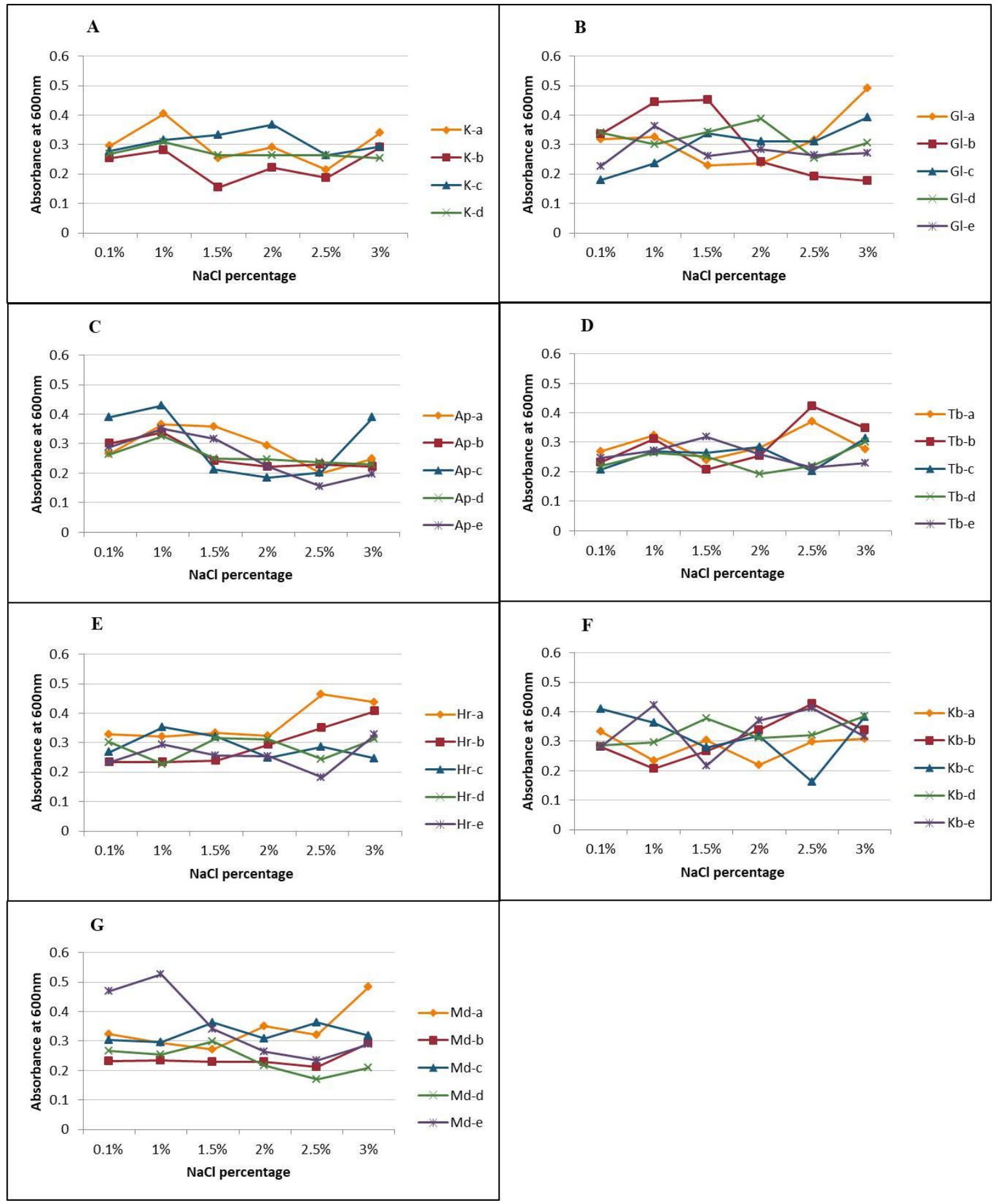

Figure 2. Growth of isolated Rhizobial strains from seven sites at different salinity levels.

Different salinity levels of the medium were obtained by changing the $\mathrm{NaCl}$ concentration. The growth of 34 Rhizobial strains was determined by the optical absorbance at $600 \mathrm{~nm}$ at $0.1 \%, 1.0 \%, 1.5 \%, 2.0 \%, 2.5 \%$ and $3.0 \% \mathrm{NaCl}$ concentrations. There was no clear relationship between growth of Rhizobial strains and $\mathrm{NaCl}$ concentration. Md-e strain showed the highest growth at $1.0 \% \mathrm{NaCl}$ among all the 34 strains.Gl-a, Ap-a,Hr-a, $\mathrm{Hr}-\mathrm{b}$, and Md-a showed a substantial growth even at $0.4 \% \mathrm{NaCl}$, the highest salinity level. A- Graph for the site Kailapathana (K). B- Graph for the site Galkulama (Gl). C- Graph for the site Anuradhapura (Ap). D- Graph for the site Thambuththegama (Tb). E- Graph for the site Horowpothana (Hr). F- Graph for the site Kebithigollewa (Kb). G- Graph for the site Medawachchiya (Md). 
was reduced (Fig. $3 \mathrm{C}$ ). All the five strains have grown well at $0.1 \%$ PEG in Thambuththegama $(>0.600)$. Tb-a showed the least growth (0.057) at $0.4 \%$ PEG and Tb-e showed the highest growth at 0.1\% PEG. Except Tb-a and Tb-d, other three strains could grow well even at $0.4 \%$ PEG (Fig. 3 D). The maximum growth was indicated by $\mathrm{Hr}-\mathrm{e}$ at $0.1 \%$ PEG while the minimum growth was indicated by $\mathrm{Hr}-\mathrm{c}$ at $0.4 \%$ PEG in the site Horowpothana. Almost all the five strains showed a better growth at $0.2 \%$ PEG $(>0.500)$. The growth level of $\mathrm{Hr}-\mathrm{a}$ is almost similar within $0.1 \%$ to $0.3 \%$ PEG concentration range (Fig. 3 E). In the site Kebithigollewa, the highest growth was observed in $\mathrm{Kb}-\mathrm{a}$ at $0.2 \%$ PEG. The growth of Kb-c (0.815) at 0.2\% PEG was almost same as the growth of Kb-a (0.821) at the same PEG concentration (Fig. 3 F). The growth of Md-b was extremely high (0.924) even at $0.4 \%$ PEG in Medawachchiya site which was the highest growth among all the 34 strains. The least growth was indicated by Md-a at 0.4\% PEG. A drastic change in growth pattern was observed in the two strains Md-a and Md-b on increasing PEG concentration from $0.3 \%$ to $0.4 \%$ (Fig. $3 \mathrm{G}$ ).

\section{Temperature tolerance of rhizobial strains}

The temperature tolerance of rhizobial strains was assessed by incubating the rhizobial strains cultured in $1 / 2$ Lupin broth at different temperatures. All the strains grew well at $35{ }^{\circ} \mathrm{C}$ ( $>0.300)$ and Hr-e showed the highest growth at $35{ }^{\circ} \mathrm{C}$. the highest growth among all the 34 strains was observed in Tb-d (0.780) at $30^{\circ} \mathrm{C}$. The strains could survive well at high temperatures compared to low temperatures $\left(25^{\circ} \mathrm{C}\right) . \mathrm{K}-\mathrm{d}, \mathrm{Tb}-\mathrm{b}, \mathrm{Hr}-\mathrm{c}$ and $\mathrm{Kb}-\mathrm{d}$ are the strains which showed a higher growth $(>0.450)$ at $45^{\circ} \mathrm{C}$ compared to other strains (Fig. 3).

K-d showed the highest growth at $45^{\circ} \mathrm{C}$ in Kailapathana and the least growth of K-b (0.304) and K-c (0.306) were almost similar (Fig. 4 A). All the 5 strains have grown well at $35^{\circ} \mathrm{C}$ in the site Galkulama while the highest growth was indicated by Gl-d at the same temperature. The least growth was observed in $\mathrm{Gl}-\mathrm{a}$ at $40{ }^{\circ} \mathrm{C}$. Almost all the five strains could survive well ( $>0.300)$ even at the highest temperature (45 $\left.{ }^{\circ} \mathrm{C}\right)$ (Fig. $4 \mathrm{~B}$ ). The rhizobial strains isolated from Anuradhapura urban area showed a better growth at $35^{\circ} \mathrm{C}$ while Ap-a showed the highest growth at the same temperature. Ap-c strain showed the minimum growth at $40^{\circ} \mathrm{C}$. All the five strains indicated a substantial growth at 35 ${ }^{\circ} \mathrm{C}$ (Fig. 4 C). The growth of Tb-d strain at $30^{\circ} \mathrm{C}$, isolated from Thambuththegama was extremely high among all the 34 strains. Tb-c also showed a significant growth at $35 \stackrel{\circ}{\circ} \mathrm{C}(0.695)$ compared to other strains. A considerable growth of the strains was observed even at 45으 C (Fig. 4 D). The maximum growth was observed in Hr-e at $35^{\circ} \mathrm{C}$ and the minimum growth was observed in $\mathrm{Hr}-\mathrm{a}$ at $40{ }^{\circ} \mathrm{C}$ in Horowpothana. The strains have equally survived under the highest and lowest temperatures (Fig. 5 E). The strain Kb-b has grown well at all the temperatures and it has showed the maximum growth at $30{ }^{\circ} \mathrm{C}$ in the site Kebithigollewa. The least growth was observed in $\mathrm{Kb}-\mathrm{c}$ at $25^{\circ} \mathrm{C}$. The growth of $\mathrm{Kb}-\mathrm{e}$ at $35^{\circ} \mathrm{C}$ and the growth of $\mathrm{Kb}-\mathrm{a}$ at $40{ }^{\circ} \mathrm{C}$ were almost similar (Fig. 4 F). In the site Medawachchiya, Md-d showed the minimum growth at $40{ }^{\circ} \mathrm{C}$. A gradually increasing growth pattern was observed in Md-b from $25^{\circ} \mathrm{C}$ to $40^{\circ} \mathrm{C}$. Md-a 


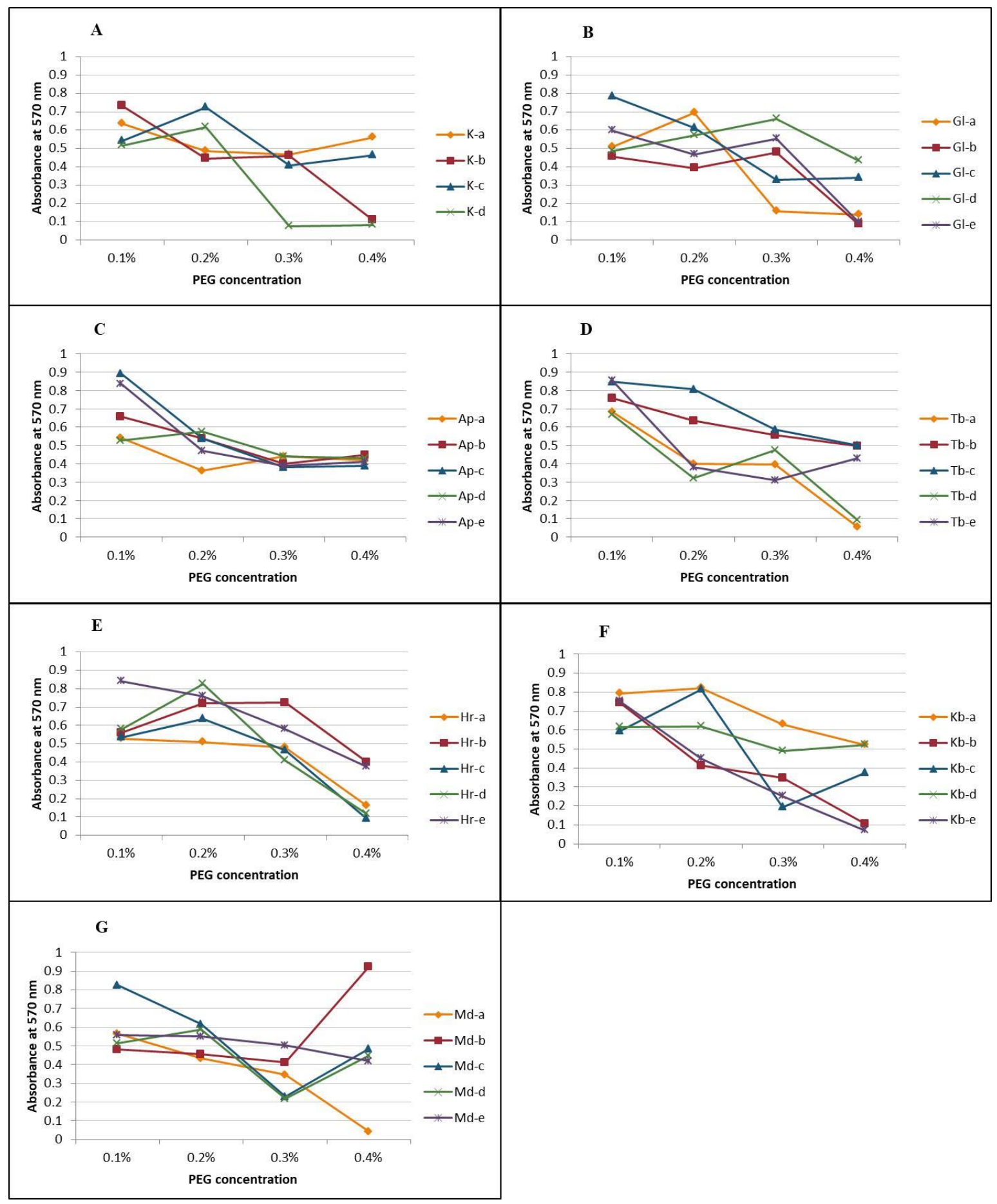

Figure 3. Growth of isolated Rhizobial strains from seven sites at different drought levels by varying PEG concentrations as $0.1 \%, 0.2 \%, 0.3 \%$ and $0.4 \%$.

The rhizobial strains were allowed to grow in the culture medium containing PEG in different amounts by incubating them in a shaker. The growth of 34 rhizobial strains was determined by measuring the UV absorption at $570 \mathrm{~nm}$. There was no clearly observable pattern of growth of the rhizobial strains in response to increasing PEG concentration. An extremely high growth was observed in Md-b strain even at $0.4 \%$ PEG and it was the highest growth among all the 34 strains. All the five strains of Kailapathana and Horowpothana have grown well at $0.1 \%$ and $0.2 \%$ PEG concentrations respectively. Other than Md-b, the strains $\mathrm{K}-\mathrm{a}, \mathrm{Tb} 0 \mathrm{~b}, \mathrm{~Tb}-\mathrm{c}, \mathrm{Kb}-\mathrm{a}$ and $\mathrm{Kb}-\mathrm{d}$ were survived well even at the highest PEG concentration (0.4\%). A- Graph for the site Kailapathana (K). BGraph for the site Galkulama (Gl). C- Graph for the site Anuradhapura (Ap). D- Graph for the site Thambuththegama (Tb). E- Graph for the site Horowpothana (Hr). F- Graph for the site Kebithigollewa (Kb). GGraph for the site Medawachchiya (Md). 


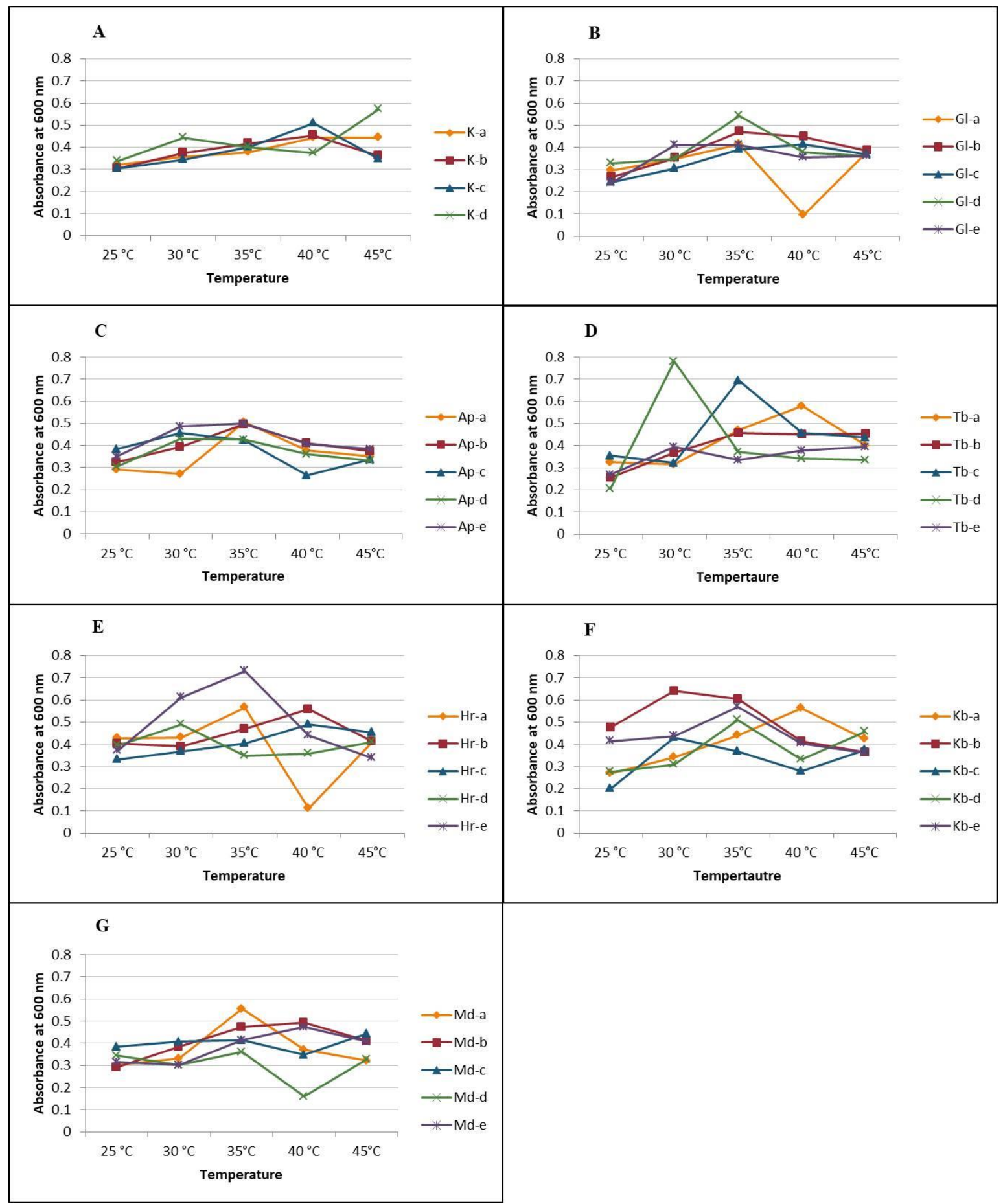

Figure 4. Growth of isolated rhizobial strains from 7 sites at different temperatures changing from $25 \stackrel{\circ}{\circ} \mathrm{C}$ to 45 $\stackrel{\circ}{\circ}$.

The growth of 35 strains at different temperatures was determined by measuring the UV absorption at $600 \mathrm{~nm}$. All most all the strains could survive well at all the temperatures except $\mathrm{Gl}-\mathrm{a}$ and $\mathrm{Hr}-\mathrm{a}$ which showed a poor growth at $40{ }^{\circ} \mathrm{C}$ compared to other strains. All the 34 strains grew considerably even at $45{ }^{\circ} \mathrm{C}$ which was the highest temperature of the series. A- Graph for the site Kailapathana (K). B- Graph for the site Galkulama (Gl). C- Graph for the site Anuradhapura (Ap). D- Graph for the site Thambuththegama (Tb). E- Graph for the site Horowpothana (Hr). F- Graph for the site Kebithigollewa (Kb). G- Graph for the site Medawachchiya (Md). 
showed the maximum growth at $35{ }^{\circ} \mathrm{C}$ in Medawachchiya (Fig. 4 G).

\section{Tolerance of rhizobial strains to combination of different physiological conditions}

The strains which showed a higher growth by indicating a higher absorbance value at more than two extreme physiological conditions were chosen mainly by considering the tolerance to three physiological conditions salinity, temperature and drought. These selected rhizobial strains were cultured in a medium with $3.0 \% \mathrm{NaCl}, 0.4 \% \mathrm{PEG}$ and $\mathrm{pH} 8.0$ and incubated at $36^{\circ} \mathrm{C}$. The $\mathrm{pH}$ value of reddish brown earth in Sri Lanka usually varies between 6.0-7.0 (Moormann and Panabokke 1961) while it varies between 5.0-8.0 in Anuradhapura district (Renuka and Senevirathne 2017). The pH 8.0 was selected as the extreme level of pH instead of $\mathrm{pH} 10.0$ as the rhizobial strains were isolated from Anuradhapura district located in dry zone of Sri Lanka. Generally, the soil temperature is not found to be as high as $45^{\circ} \mathrm{C}$ in this district. Thereby, the selected rhizobial strains were grown at $36^{\circ} \mathrm{C}$.

When the rhizobial strains which showed tolerance to adverse physiological conditions separately were cultured in a medium with combined physiological conditions, some of the strains showed a poor growth. The highest growth was observed in Kb-d strain among all the 15 strains. The four strains Gl-a, Ap-e, and Hr-a showed a poor growth compared to other strains while Hr-a showed the lowest growth among all the strains. Except these four strains, the remaining 11 strains grew considerably under these extreme physiological conditions (Fig. 5)

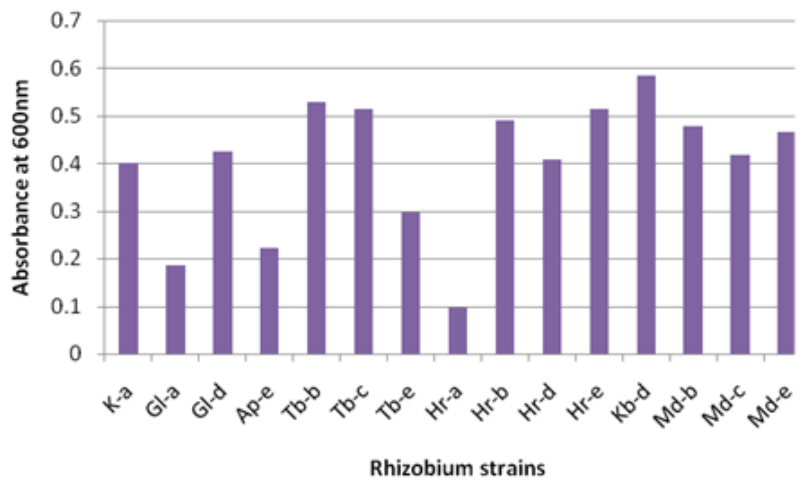

Figure 5. Growth of 15 selected rhizobial strains under combination of different physiological conditions.

These 15 strains were cultured in a medium with $3.0 \% \mathrm{NaCl}, 0.4 \%$ PEG and $\mathrm{pH} 8.0$ and incubated at $36{ }^{\circ} \mathrm{C}$ and the growth was determined by measuring the absorbance at $600 \mathrm{~nm}$. The highest growth was indicated by $\mathrm{Kb}-\mathrm{d}$ and the lowest growth was indicated by $\mathrm{Hr}-\mathrm{a}$ under these extreme physiological conditions.

\section{Quantification of genomic DNA}

The genomic DNA quantification was carried out to check whether there is a sufficient amount of DNA to conduct PCR. The DNA concentration in $\mathrm{K}-\mathrm{a}$ and Gl-d strains was low compared to other 13 strains. But DNA quantities of those samples were sufficient to carry out the PCR. The purity of extracted genomic DNA was not so high and it was not taken in to consideration as there was an adequate amount of DNA to perform the PCR and to precede further analysis (Table 1). 
Table 1 Purity and the concentrations of genomic DNA extracted from 15 selected rhizobial strains

\begin{tabular}{ccccc}
\hline $\begin{array}{c}\text { Rhizobial } \\
\text { strain }\end{array}$ & $\begin{array}{c}\text { Absorbance } \\
\text { at 260 } \mathbf{~ n m} \\
\text { (A260) }\end{array}$ & $\begin{array}{c}\text { Absorbance } \\
\text { at 280 nm } \\
\text { (A280) }\end{array}$ & $\begin{array}{c}\text { Purity } \\
\text { (A260/A280) }\end{array}$ & $\begin{array}{c}\text { Concentration } \\
\text { of DNA } \\
(\boldsymbol{\mu g} / \mathbf{m l})\end{array}$ \\
\hline K-a & 0.0187 & 0.0236 & 0.7923 & 187 \\
Gl-a & 0.2202 & 0.2737 & 0.8045 & 2202 \\
Gl-d & 0.0194 & 0.0206 & 0.9417 & 194 \\
Ap-e & 0.2641 & 0.3225 & 0.8189 & 2641 \\
Tb-b & 0.0955 & 0.1168 & 0.8176 & 955 \\
Tb-c & 0.1292 & 0.1603 & 0.8059 & 1292 \\
Tb-e & 0.2929 & 0.3668 & 0.7985 & 2929 \\
Hr-a & 0.1218 & 0.1497 & 0.8316 & 1218 \\
Hr-b & 0.0770 & 0.0943 & 0.8165 & 770 \\
Hr-d & 0.2653 & 0.3324 & 0.7981 & 2653 \\
Hr-e & 0.0472 & 0.0395 & 1.1949 & 472 \\
Kb-d & 0.0519 & 0.0547 & 0.9488 & 519 \\
Md-b & 0.0391 & 0.0440 & 0.8886 & 391 \\
Md-c & 0.0431 & 0.0468 & 0.9209 & 431 \\
Md-e & 0.0596 & 0.0725 & 0.8220 & 596 \\
\hline
\end{tabular}

\section{Genetic diversity and relationship between selected rhizobial strains}

The amplified DNA fragments of the selected 15 rhizobial strains obtained through PCR were visualized using agarose gel electrophoresis. The DNA banding patterns were highly polymorphic and some of the bands were notable compared to other bands and they were common for many strains. K-a, Tb-e, Hr-a, Hr-b and Md-b showed the same banding pattern (Fig. 6). A dendrogram was prepared to analyse the genetic diversity and interconnection between selected 15 rhizobial strains by using the banding patterns obtained for ERIC profiling complete linkage Euclidean distance. K-a, Tb-e, Hr-a, Hr-b and Mdb were similar to each other at $100 \%$ similarity level. The next level was observed at $71 \%$ where there were 9 clusters. K-a, Tb-c, Tb-e, Hr-a, Hr-b and Md-b belong to one cluster. Tb-b and Hr-d belong to one cluster and remaining 7 strains belong to 7 separate clusters. Gl-a was similar to Tb-b and Hr-d and Kb-d was similar to Md-e at 57\% similarity level (Fig. 7).

\section{Discussion}

The rhizobial strains inhabiting $G$. sepium were isolated from seven sites (Kailapathana, Galkulama, Anuradhapura urban area, Kebithigollewa, Medawachchiya, Thambuththegama, Horowpothana) in Anuradhapura district. G. sepium was widely distributed throughout the district as it was grown in home gardens as live fence and in 


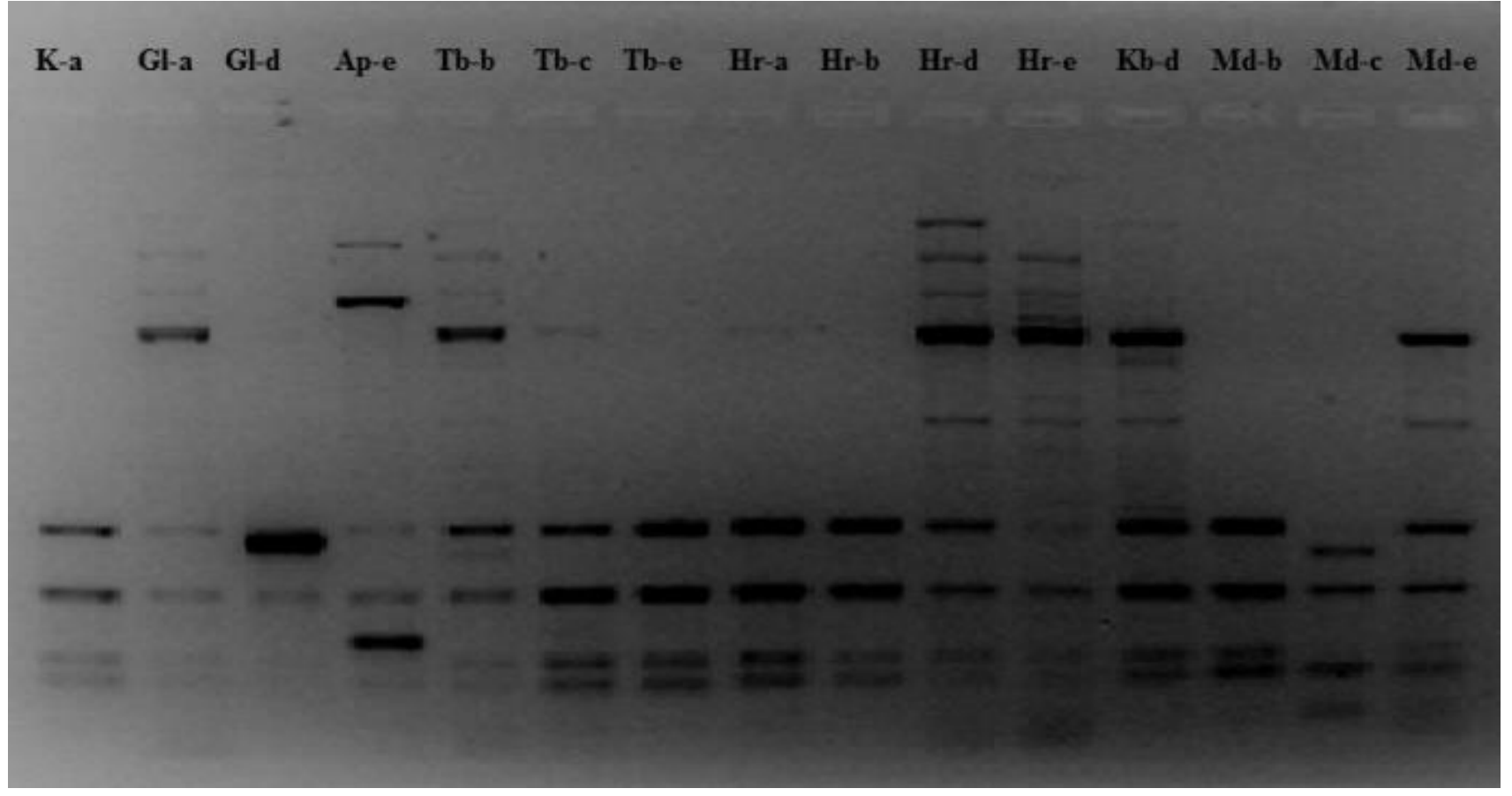

Figure 6. The gel image of ERIC profiling for 15 rhizobial strains.

DNA fingerprinting for 15 selected rhizobial strains were performed using ERIC 1R and ERIC 2R primers. DNA banding patterns were highly polymorphic. Some bands were prominent and observed in many strains. A similar banding pattern was observed in the strains K-a, Tb-e, Hr-a, Hr-b and Md-b.

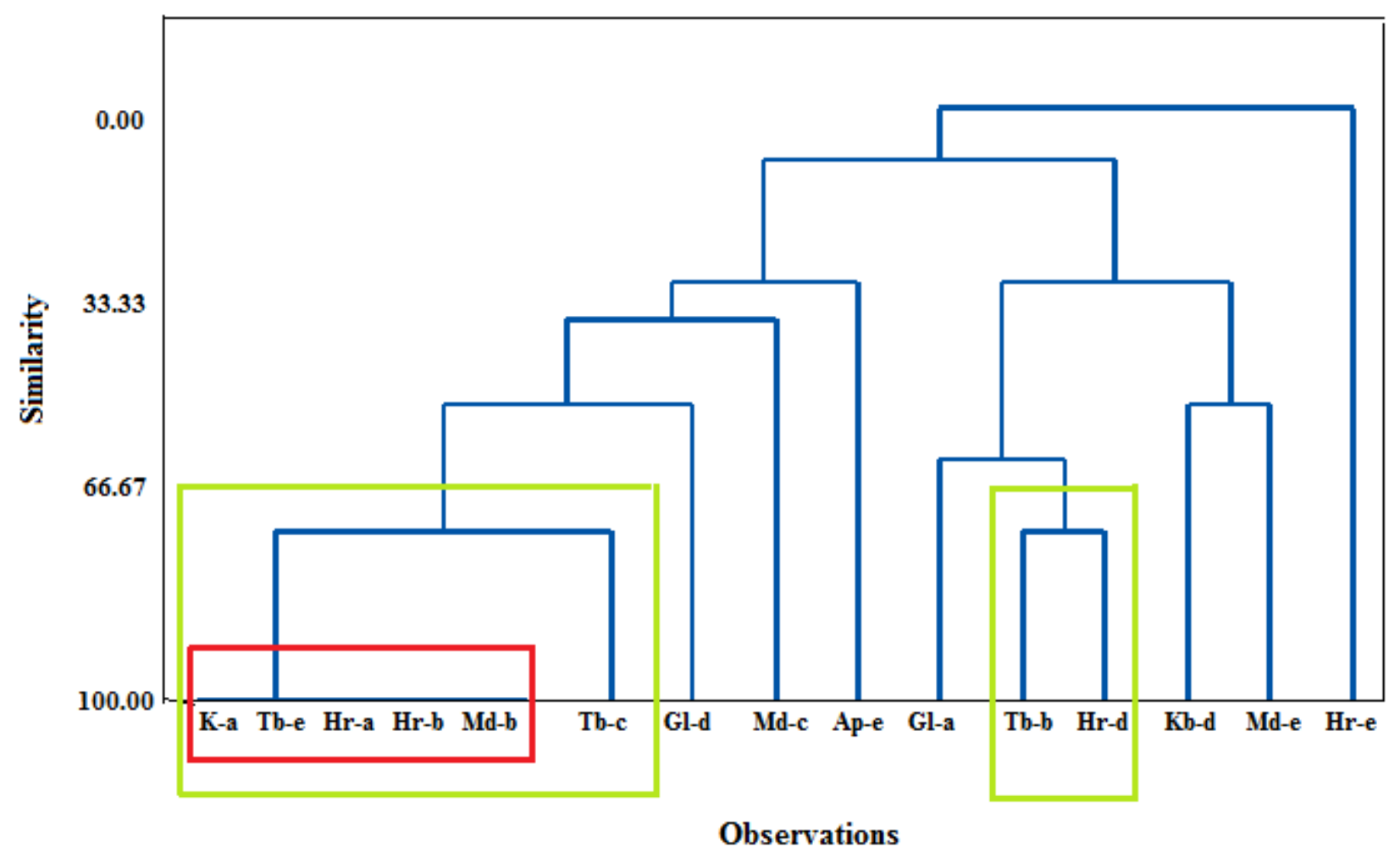

Figure 7. Dendrogram showing the genetic relationship between selected 15 Rhizobium strains.

The dendrogram was prepared using complete linkage euclidean distance using statistical software MINITAB 18. K-a, Tb-e, Hr-a, Hr-b and Md-b show 100\% similarity. 9 Clusters can be observed at 71\% similarity level and 8 clusters can be observed at 59\% similarity level. 
agricultural lands mainly as a crop support and as a shade tree. The root nodules were present closer to the surface soil and they were almost absent in deeper soil layers. The nodules were distributed along the tiny lateral roots of the root material and they were found mostly as individuals while some of them were found as clumps in some sites (Kailapathana and Anuradhapura urban area). This type of root nodule distribution may occur as the root nodules require oxygen in large amounts to carry out BNF and also the low concentrations of $\mathrm{O}_{2}$ tend to suppress the formation and activity of nodules (Weisz and Sinclair 1987).

The root nodules were collected from seven sites to have a total collection of 34 rhizobial strains and their tolerance for various physiological conditions were analysed by growing them under different $\mathrm{pH}$, salinity levels, drought conditions and different temperatures. According to the results obtained for $\mathrm{pH}$ tolerance of these isolated rhizobial strains, all the strains showed their highest growth within $\mathrm{pH}$ 5.0-7.0 while Md-d and Md-c strains of Medawachchiya site showed a considerable growth even at alkaline $\mathrm{pH}(\mathrm{pH} 8.0$ - 10.0) (Fig. 1). The strains Ap-c, Ap-e, Kb-c, Mdc, Md-d grew considerably even at highly acidic $\mathrm{pH}(\mathrm{pH} 3.0$ - 4.0). These results indicate that the isolated rhizobial strains have a $\mathrm{pH}$ tolerance over a wide range. Most of the rhizobial strains exhibit their optimum growth at pH $6.0-7.0$ (Somasegaran and Hoben 1994) and the $\mathrm{pH}$ value of reddish brown earth found in dry zone of Sri Lanka usually vary between 6.0-7.0, which may increase with depth (Moormann and Panabokke 1961). However according to Renuka and Senevirathne (2017), pH of the soil found in
Anuradhapura varies from 5.0 to 8.0. Generally, highly acidic $\mathrm{pH}(1.0$ and 2.0$)$ conditions are not found in natural soil. Therefore, $\mathrm{pH}$ tolerance of rhizobial strains was determined within $\mathrm{pH}$ 3.010.0 range. Most of the rhizobial strains isolated from the district exhibited the expected results except few strains which were identified as $\mathrm{pH}$ tolerant strains as they could survive up to a certain extent even at highly acidic and highly alkaline $\mathrm{pH}$. There was no relationship between the $\mathrm{pH}$ tolerance of the rhizobial strains and the environmental conditions of the sampling site as almost all the seven sampling sites had similar environmental conditions. Most of the legumes which depend on symbiotic $\mathrm{N}_{2}$ fixation grow well at slightly acidic or neutral $\mathrm{pH}$ and nodulation occurs between $\mathrm{pH} 5.5-7.2$ to a great extent (Brockwell et al. 1995). Highly acidic pH in soil affects the initial activities of infection process, nodulation and molecular signalling between the host plant and the microsymbiont, the Rhizobium species (Hungria and Vargas 2000). But acidic $\mathrm{pH}$ tolerant rhizobial strains are capable of maintaining 7.2 - 7.5 intracellular $\mathrm{pH}$ even at highly acidic pH (Kashket 1985; Graham et al. 1994). These facts give the reason for the higher growth of most of the rhizobial strains between pH 5.0 - 7.0 and also for the considerable growth patterns of few strains even at highly acidic $\mathrm{pH}$.

Many studies indicate that salt stress has adverse effects on legume-Rhizobium symbiosis and also nodule formation (Zahran 1991; Zahran and Sprent 1986). The high salinity levels tend to decrease the respiration of the nodules and production of cytosolic proteins especially, Leghemoglobin which plays an important role in BNF (Delgado et al. 1993). Rhizobium meliloti and 
Rhizobium leguminosarum have been identified as some of the salt tolerant rhizobial strains which belong to the genera Rhizobium as they could survive at $300-700 \mathrm{mM} \mathrm{NaCl}$ and upto 350 $\mathrm{mM} \mathrm{NaCl}$ concentrations respectively (Embalomatis et al. 1994; Breedveld et al. 1991). Rhizobia inhabiting woody legumes such as Acacia, Leucaena and Prosopis were found to be salt tolerant to $500-850 \mathrm{mM} \mathrm{NaCl}$ (Lal and Khanna 1995; Zhang et al. 1991). It was found that many of the rhizobial strains withstand the high saline conditions by intracellular accumulation of osmolytes (Csonka and Hanson 1991) as the levels of intracellular glutamate, $\mathrm{K}^{+}$ and $\mathrm{N}$ - acteylglutaminyl-glutamine amide were increased during salt stress in R. meliloti. In all the sites, most of the strains showed a considerable growth even at high salt concentration $(>0.3)$ indicating that there are many salt tolerant strains among the isolated rhizobial strains. Although Md-e strain showed the highest growth at $1.0 \% \mathrm{NaCl}$ among all the 34 strains, four sites out of seven sampling sites showed their highest growth at high salinity levels (2.5\% and 3.0\%) (Fig. 2). Generally, the accumulation of salt in dry zone soil is high as the evaporation occurs in large amounts within the zone. Therefore, many of the Rhizobium species exist in dry soil have the ability to survive well under saline conditions by using the osmotic adaptation mechanism and this may the possible reason for the higher growth levels of most of the rhizobial strains even at high $\mathrm{NaCl}$ concentrations.

The evaporation which occurs in Anuradhapura district is relatively high as it is located in dry zone of Sri Lanka which in turn results in water deficiency. This district receives an average annual rainfall of $1368 \mathrm{~mm}$ (Department of Meteorology, Sri Lanka). During Yala season which runs from late March to mid-May, the district receives about $300 \mathrm{~mm}$ of rain only. Therefore, the district experiences a water scarcity specifically in this period which is almost like a drought condition enabling only drought tolerant crops to survive (Handawela 1992). G. sepium prefers growing in warm seasonally dry climates in which rainfall varies between $900 \mathrm{~mm}$ - 1500 mm (Elevitch and Francis 2006). Most of the rhizobial strains grew well at low PEG concentrations and a reduction in growth was observed with the increase of PEG concentration. This is because water deficiency leads to the irregular morphology of Rhizobia which causes a reduction in infection and nodulation. It was found that formation of infection thread and nodulation in Vicia faba plants were reduced to a great degree when a water deficient condition was induced with the help of PEG (Zahran 1986). But most of the strains in each sampling site showed a higher growth even at $0.4 \%$ PEG. This indicates that most of the isolated rhizobial strains have the ability to tolerate drought stress and they are adapted for this water deficient environmental condition which is very common in dry zone of Sri Lanka. Specifically, Md-b from Medawachchiya site showed an extremely high growth among all the 34 strains $(>0.9)$ even at the highest PEG concentration (Fig. 3).

Mean monthly temperature of the district varies between $27{ }^{\circ} \mathrm{C}-28.7{ }^{\circ} \mathrm{C}$ while mean maximum temperature of the month varies between $26.2^{\circ} \mathrm{C}$ to $33.9{ }^{\circ} \mathrm{C}$. But some areas of Anuradhapura have exhibited $39{ }^{\circ} \mathrm{C}$ as the weekly maximum 
temperature (Handawela 1992). Therefore, the isolated rhizobial strains showed a high tolerance to high temperatures. Most of the strains (K-a, Kd, Tb-b, Tb-c, Hr-a, Hr-b, Hr-c, Kb-a, Kb-d, Md-b, Md-c and Md-e) grew well even at $45{ }^{\circ} \mathrm{C}(>0.400)$ and K-d is showed the highest growth (0.572) among all of them (Fig. 4), almost all the strains showed a low growth level at $25^{\circ} \mathrm{C}$ by indicating their adaptation to grow at high temperatures as high temperature environmental conditions are natural and common within the district belonging to dry zone.

The 15 rhizobial strains were selected for the final analysis based on their higher absorbance values obtained for the different physiological conditions separately. The natural environmental conditions of Anuradhapura district were taken in to consideration when determining their tolerance for combined physiological conditions. The $\mathrm{pH}$ was selected as 8.0 because $\mathrm{pH}$ of dry zone soil does not increase up to $\mathrm{pH} 10.0$ and the tolerance test was carried out at $36^{\circ} \mathrm{C}$. This is because; a high temperature like $45{ }^{\circ} \mathrm{C}$ usually does not exist in soil. According to the water deficiency and saline conditions in dry zone soil due to the higher amounts of evaporation, the PEG concentration and $\mathrm{NaCl}$ concentration were selected as $0.4 \%$ and $3.0 \%$ to determine the tolerance of 15 rhizobial strains for drought stress and salinity stress respectively. Kb-d showed the highest growth among 15 strains while Hr-a showed the lowest growth. However, out of 15 strains only three strains Gl-a, Ap-e and Hr-a exhibited low levels of growth while remaining 12 strains showed a better growth as expected by indicating their tolerance to extreme physiological conditions (Fig. 5). This is because
Gl-a and $\mathrm{Hr}-\mathrm{a}$ could not survive well at $0.4 \%$ PEG though they showed tolerance for high temperature $\left(45^{\circ} \mathrm{C}\right)$ and salinity level $(3.0 \%$ $\mathrm{NaCl})$. Therefore, extreme drought stress might be the possible factor which limits the growth of Gl-a and Hr-a. When considering the poor growth of Ap-e, high salinity level may be the limiting factor as Ap-e showed a poor growth at 3.0\% $\mathrm{NaCl}$ though it could survive well under $45^{\circ} \mathrm{C}$ and drought stress (0.4\% PEG).

The 15 selected rhizobial strains exhibited a high polymorphism when they were subjected to ERIC profiling in order to analyze their genetic diversity (Fig. 6). When preparing the dendogram to determine the diversity of 15 rhizobial strains, the band number 16 was not included as it showed monomorphism. Therefore, only the bands showed polymorphism were considered when constructing the dendogram using complete linkage Euclidean distance. The strains $\mathrm{K}-\mathrm{a}, \mathrm{Tb}-\mathrm{c}, \mathrm{Tb}-\mathrm{e}, \mathrm{Hr}-\mathrm{a}, \mathrm{Hr}-\mathrm{b}$ and Md-b belong to a single cluster by indicating the close relationship between them. Except the strain $\mathrm{Tb}-\mathrm{c}$, the remaining strains belonging to this cluster show $100 \%$ similarity. The absorbance values at 600 nm obtained for the growth of K-a, Tb-c, Hr-b, and Md-b under combined physiological conditions are somewhat close to each other and this result support the close relationship between them to a certain degree. Though $\mathrm{Tb}-\mathrm{e}$ and $\mathrm{Hr}-\mathrm{a}$ showed different growth levels from other strains under combined physiological conditions they belong to the same cluster. The strains Tb-b and Hr-d belong to one cluster. The strain Hr-e is highly diverse from other strains as it belongs to an individual lineage. When considering the relationship between these strains at $71 \%$ 
similarity level, these 15 strains fall in to 9 clusters. They are genetically diverse in nature (Fig. 7). The dendrogram prepared based on the inverse gel image of ERIC profiling for 15 rhizobial strains did not provide sufficient evidence to prove the relationship between the diversity of Rhizobium sp. and the sampling site.

\section{Conclusion}

The rhizobial strains isolated from $G$. sepium in Anuradhapura district showed a considerable tolerance over a wide range of different physiological conditions $\mathrm{pH}$, salinity, drought and temperature as they have adapted to these extreme environmental conditions experienced by the host plant $G$. speium in their natural environment. Out of 34 rhizobial strains isolated, 15 strains showed the best tolerance for extreme physiological conditions. Therefore, these 15 strains can be utilized in cross inoculation of crop legumes. Three strains among 15 strains could not survive well under combined extreme physiological conditions while remaining 12 strains could survive well under the same conditions. According to the dendrogram constructed using ERIC profiling, these 15 strains were genetically diverse in nature.

These unknown rhizobial strains can be identified with reference to known rhizobial strains using molecular techniques such as $16 \mathrm{~s}$ RNA sequences in further studies. Effective rhizobial inoculants can be developed through further analysis of their stress response and symbiosis genes to introduce more efficient and effective agricultural practices for a sustainable agriculture.

\section{References}

Awonaike K O, Hardarson G, Kumarasingha K S (1992) Biological nitrogen fixation of Gliricidia sepium/Rhizobium symbiosis as influenced by plant genotype, bacterial strain and their interactions. Tropical agriculture 69: 381-385.

Bohlool B B, Ladha J K, Garrity D P, George T (1992) Biological nitrogen fixation for sustainable agriculture. A perspective. Plant soil. 141(1-2): 1-11.

Breedveld M W, Zevenhuizen L P, Zehnder A J (1991) Osmotically-regulated trehalose accumulation and cyclic $\beta$ - $(1,2)$-glucan excretion by Rhizobium leguminosarum biovar trifolii TA1. Arch Microbiol 156(6): 501-506.

Brockwell J, Bottomley P J, Thies J E (1995) Manipulation of rhizobia microflora for improving legume productivity and soil fertility: a critical assessment. Plant soil 174(1-2): 143-80. Burns R C, Hardy R W F (1975) Nitrogen fixation in bacteria and higher plants. Springer-Verlag. New York.

Chadhokar P A (1982) Gliricidia maculata: a promising legume fodder plant [in Sri Lanka]. World Animal Review.

Cheng Q (2008) Perspectives in biological nitrogen fixation research. J Integr Plant Biol 50(7): 786-798.

Csonka L N, Hanson A D (1991) Prokaryotic osmoregulation: genetics and physiology. Annu Rev Microbiol 45(1): 569-606.

Delgado M J, Garrido J M, Ligero F, Lluch C (1993) Nitrogen fixation and carbon metabolism by nodules and bacteroids of pea plants under 
sodium chloride stress. Physiol Plant 89: 824829.

Elevitch C R, Francis J K (2006) Gliricidia sepium (gliricidia). Species profile for Pacific Island agroforestry in Elevitch C R (Ed). Permanent Agriculture Resources. Hawaii.

Embalomatis A, Papacosta D K, Katinakis P (1994) Evaluation of Rhizobium meliloti strains isolated from indigenous populations northern Greece. Journal of Agriculture and Crop Sciences 172: 73-80.

Graham P H, Draeger K J, Ferrey M L, Conroy M J, Hammer B E, Martinez E, Aarons S R, Quinto C (1994) Acid pH tolerance in strains of Rhizobium and Bradyrhizobium, and initial studies on the basis for acid tolerance of Rhizobium tropici UMR1899. Can J Microbiol 40(3): 198-207.

Gunaratne W D L, Heenkenda A P, Premakumara K V S, Bandara W M S R (2000) Biological $N_{2}$ fixing capacity of Gliricidia sepium and Calliandra calothyrsus under different agroclimatic conditions. Trop Agric Res 3(1): 32-38.

Handawela J (1992) Anuradhapura district environmental profile: final draft report.

Hulton C S J, Higgins C F, Sharp P M (1991) ERIC sequences: a novel family of repetitive elements in the genomes of Escherichia coli, Salmonella typhimurium and other enterobacteria. Mol Microbiol 5: 825-834.

Hungria M, Vargas M A T (2000) Environmental factors affecting $\mathrm{N}_{2}$ fixation in grain legumes in the tropics, with an emphasis on Brazil. Field Crops Res 65: 151-164.

Jayasundara H P S, Dennet M D, Sangakkara U R (1997) Biological nitrogen fixation in Gliricidia sepium and Leucaena leucocephala and transfer of fixed nitrogen to an associated grass. Tropical grasslands 31: 529-537.

Kashket E R (1985) The proton motive force in bacteria: a critical assessment of methods. Annual review of microbiology 39(1): 219-242.

Kumar P R, Ram M R (2012) Production of indole acetic acid by Rhizobium isolates from Vigna trilobata (L) Verdc. Afr J Microbiol Res 6(27): 5536-5541.

Kumari S, Sinha S P (2001) Symbiotic and asymbiotic $\mathrm{N}_{2}$ fixation. Centre of advanced study in botany. Banaras hindu university 5: 134-145.

Kulasooriya S A (2008) Biological Nitrogen Fixation. Fundamentals and Utilization. Science Education Unit. University of Peradeniya, Sri Lanka. ISBN 978-955-589-108-0: 143.

Lal B, Khanna S (1995) Selection of salt tolerant Rhizobium isolates of Acacia nilotica. World J Microbiol Biotechnol 10: 637-639.

Laranjoa M, Alexandrea A, Oliveiraa S (2014) Legume growth-promoting rhizobia: An overview on the Mesorhizobium genus. Microbiol Res 169: 2-17.

Lavin M, Mathews S, Hughes C (1991) Chloroplast DNA variation in Gliricidia sepium (Leguminosae) intraspecific phylogeny and tokogeny. Am J Bot 78: 1576-1585.

Liyanage M de S, Danso S K A, Jayasundara H P S (1994) Biological nitrogen fixation in four Gliricidia sepium genotypes. Plant soil 161: 267274.

Liyanage D V, Wickramaratne M R T, Jayasekara C (1988) Coconut breeding in Sri Lanka: a review. Cocos 6: 1-26. 
Moormann F R, Panabokke C R (1961) Soils of Ceylon. Government press, Ceylon. pp 738.

Niemann S, Kalinowski T D, Nagel A, Puhler A, Selbitschka W (1999) Genetic basis of enterobacterial repetitive intergenic consensus (ERIC)-PCR fingerprint pattern in Sinorhizobium meliloti and identification of S. meliloti employing PCR primers derived from an ERIC-PCR fragment. Arch Microbiol 172: 22-30.

Paul E A (1988) Towards the year 2000: directions for future nitrogen research. In Wilson $\mathrm{J}$ R (ed). Advances in nitrogen cycling in agricultural ecosystems. Wallingford, United Kingdom: CAB International pp. 417-425.

Peoples M B, Brockwell J, Herridge D F, Rochester I J, Alves B J, Urquiaga S, Boddey R M, Dakora F D, Bhattarai S, Maskey S L, Sampet C (2009) The contributions of nitrogen-fixing crop legumes to the productivity of agricultural systems. Symbiosis 48(1-3): 1-7.

Peoples M B, Herridge D E, Ladha J K (1995) Biological nitrogen fixation: An efficient source of nitrogen for sustainable agricultural production. Plant Soil 174: 3-28.

Rai M (2006) Handbook of microbial biofertilizers. CRC Press.

Renuka K A, Senavirathna W M I (2017) Soil nutrient status of big onion growing areas in Anuradhapura district of Sri Lanka. Annals of Sri Lanka department of agriculture 19(2): 53-59.

Samarakoon S M N S, Rajapakse S (2020) Identification of stress tolerant rhizobial strains inhabiting Gliricidia sepium in the Polonnaruwa district. Sri Lanka. Ceylon J Sci. 49 (1) 37-47.
Sharples G J, Lloyd R G (1990) A novel repeated DNA sequence located in the intergenic regions of bacterial chromosomes. Nucleic Acids Res 18(22): 6503-6508.

Simons A, Stewart J (1994) 2.2 Gliricidia sepium-a Multipurpose Forage Tree Legume.

Somasegaran P, Hoben H J (1994) Handbook for Rhizobia. Edwards Brothers Inc, USA.

Sprent J I, Sprent P (1990) Nitrogen fixing organisms. Pure and applied aspects. London. United Kingdom.

Sprent J I (2009) Legume nodulation: a global perspective. John Wiley \& Sons.

Stamford N P, Ortega A D, Temprano F, Santos D R (1997) Effects of phosphorus fertilization and inoculation of Bradyrhizobium and mycorrhizal fungi on growth of Mimosa caesalpiniaefolia in an acid soil. Soil Biol Biochem 29(5-6): 959-964.

Weisz P R, Sinclair T R (1987) Regulation of soybean nitrogen fixation in response to rhizosphere oxygen II. Quantifi cation of nodule gas permeability. J Plant Physiol 84: 906-910.

Wilson L A, Sharp P M (2006) Enterobacterial repetitive intergenic consensus (ERIC) sequences in Escherichia coli: Evolution and implications for ERIC-PCR. Mol Biol Evol 23(6): 1156-1168.

Zahran H H (1986) Effect of sodium chloride and polyethylene glycol on rhizobial root hair infection. root nodule structure and symbiotic nitrogen fixation in Vicia faba L. plants. Ph.D. thesis. Dundee University Dundee. Scotland 
Zahran H H, Sprent J I (1986) Effects of sodium chloride and polyethylene glycol on root-hair infection and nodulation of Vicia faba L. plants by Rhizobium leguminosarum. Planta 167(3): 303309.

Zahran H H (1991) Conditions for successful Rhizobium-legume symbiosis in saline environments. Biol Fertil Soils 12: 73-80.
Zahran H H (1999) Rhizobium-legume symbiosis and nitrogen fixation under severe conditions and in an arid climate. Microbiology and molecular biology reviews 63(4): 968-989.

Zhang X P, Karsisto M, Harper R, Lindstrom K (1991) Diversity of Rhizobium bacteria isolated from the root nodules of leguminous trees. Int J Syst Bacteriol 41: 104-113. 